R. Heidenhain: Färbung mit Hämatoxylin und chromsauren Salzen. 383

\title{
Eine Abänderung der Färbung mit Hämatoxylin und chromsauren Salzen.
}

Briefliche Mittheilung an Prof. Waldeyer.

Von

\section{R. Heidenhain.}

Die von mir vor einiger Zeit beschriebene Färbung mit Hämatoxylin und Kali bichromicum hat den Nachtheil, dass die ursprünglich schwarz tingirten Präparate leicht vergilben und damit unbrauchbar werden. Die folgende Abänderung des Verfahrens ist von diesem Uebelstande frei.

Die in Alkohol oder besser zuerst in Pikrinsäure (gesättigte Lösung) und darauf in Alkohol erhärteten Gewebsstiucke werden auf 12-24 Stunden in eine wässerige Lösung von Hämatoxylin $(1 / 3 \%)$ und darauf in eine $1 / 2 \%$ ige Lösung des gelben einfach chromsauren Kali's (statt des rothen doppelt ehromsauren Kali's), ebenfalls auf 12-24 Stunden gebracht. Sodann Entwässerung in Alkohol, Durchtränkung mit Xylol, Einschmelzen in Paraffin.

Feine Schnitte, in Xylol aufgehellt, zeigen eine graublane Färbung, welche das Chromatin der Kerne wie die protoplasmatischen Strukturen annehmen. Man erhält damit ausgezeichnete Tinktion der Protoplasmanetze (z. B. in Schleimzellen, Becherzellen u. s. f.), sowie ganz reine Kerntinktionen.

Bei Vorbehandlung mit Pikrinsäure eignet sich diese Methode vorzüglich znm Studium der Mitosen und hat vor den üblichen Behandlungsweisen zur Darstellung der letzteren den Vorzug, dass 
384 R. Heidenhain: Färbung mit Hämatoxylin und chromsauren Salzen.

sie Stückfärbung (natïrlich dürfen nur kleine Stïcke benutzt werden) statt der Färbung einzelner Schnitte gestattet. Ich babe bei Säugethier-Geweben nie schönere Mitosen-Bilder gesehen, als sie z. B. die Lieberküh n'schen Drüsen nach jener Behandlungsweise zeigen. Hier trifft man nämlich unter Umständen auf eine selten reichliche Kerntheilung, worüber bald Näheres mitzutheilen ich mir vorbehalte. Die Chromatinfäden zeigen of auf das Deutlichste die Zusammensetzung aus Körnchen, die ich bei Säugethieren mit Anwendung der bisherigen Methoden nie habe sehen können. 